\title{
Ku-band radar penetration into snow cover on Arctic sea ice using airborne data
}

\author{
Rosemary WILLATT, ${ }^{1}$ Seymour LAXON, ${ }^{1}$ Katharine GILES, ${ }^{1}$ Robert CULLEN, ${ }^{2}$ \\ Christian HAAS, ${ }^{3}$ Veit HELM ${ }^{4}$ \\ ${ }^{1}$ National Centre for Earth Observation - Centre for Polar Observation and Modelling, University College London, \\ Gower Street, London WC1E 6BT, UK \\ E-mail: rcw@cpom.ucl.ac.uk \\ ${ }^{2}$ European Space Agency/European Space Research and Technology Centre (ESTEC), Keplerlaan 1, 2201 AZ Noordwijk, \\ The Netherlands \\ ${ }^{3}$ Department of Earth \& Atmospheric Sciences, University of Alberta, Edmonton, Alberta T6G 2E3, Canada \\ ${ }^{4}$ Alfred Wegener Institute for Polar and Marine Research, Am Allen Hafen 26, D-27568 Bremerhaven, Germany
}

\begin{abstract}
Satellite radar altimetry provides data to monitor winter Arctic sea-ice thickness variability on interannual, basin-wide scales. When using this technique an assumption is made that the peak of the radar return originates from the snow/ice interface. This has been shown to be true in the laboratory for cold, dry snow as is the case on Arctic sea ice during winter. However, this assumption has not been tested in the field. We use data from an airborne normal-incidence Ku-band radar altimeter and in situ field measurements, collected during the CryoSat Validation Experiment (CryoVEx) Bay of Bothnia, 2006 and 2008 field campaigns, to determine the dominant scattering surface for Arctic snow-covered sea ice. In 2006, when the snow temperatures were close to freezing, the dominant scattering surface in $25 \%$ of the radar returns appeared closer to the snow/ice interface than the air/snow interface. However, in 2008, when temperatures were lower, the dominant scattering surface appeared closer to the snow/ice interface than the air/snow interface in $\mathbf{8 0} \%$ of the returns.
\end{abstract}

\section{INTRODUCTION}

Satellite radar altimetry provides a method for determining winter Arctic sea-ice thickness variability on interannual, basin-wide scales (Laxon and others, 2003; Giles and others, 2008). The two-way travel times of the radar pulse from sea ice, and adjacent water, are measured. The difference between these times is converted to a distance corresponding to the elevation of the snow/ice interface above the sea surface, which Giles and others (2007) define as sea-ice freeboard. The freeboard is then converted to thickness using the assumption of hydrostatic equilibrium between the sea ice, snow cover and sea water.

The assumption that the radar return originates at the snow/ice interface is based on a laboratory experiment (Beaven and others, 1995) that showed that for a dry, cold snow cover a $13.4 \mathrm{GHz}$ beam at normal incidence the radar return originates from the snow/ice interface. Satellite radar altimetry data from the winter (defined as October-March in the Arctic) are therefore used to determine sea-ice thickness with the assumption that the radar return is from the snow/ ice interface when the snow is cold and dry (Laxon and others, 2003; Giles and others, 2008). Howell and others (2005) state that the dielectric properties of water will dominate over those of dry snow for volumetric water contents of $1 \%$ or more, and Garrity (1992) reports significant liquid water content in snow on sea ice at temperatures between $-5^{\circ} \mathrm{C}$ and $0^{\circ} \mathrm{C}$. However, during the Surface HEat Budget of the Arctic ocean (SHEBA) project, snow temperatures on Arctic sea ice from November to March were lower than this, between $-11^{\circ} \mathrm{C}$ and $-40^{\circ} \mathrm{C}$ at the snow surface and between $-16^{\circ} \mathrm{C}$ and $-6^{\circ} \mathrm{C}$ at the snow/ ice interface (Persson and others, 2002). This indicates that the snow cover is cold and dry during Arctic winter and that the assumption of the radar return originating at the snow/ ice interface should hold.

The detection of Arctic snowmelt and freeze-up (Smith, 1998; Howell and others, 2008; Markus and others, 2009) using passive microwave data also indicates that microwave properties start to change as temperatures approach the melting/freezing point. Smith (1998) and Markus and others (2009) showed that snow does not melt in the central Arctic during winter.

Comparisons between laser and radar altimetry also provide evidence for the penetration of Ku-band radar into snow on sea ice. Assuming a radar altimeter measures the ice surface elevation, whereas the laser ranges to the snow surface (Kwok and others, 2004), differences in elevation measured by radar and laser altimeters should represent the snow depth. This elevation difference has been investigated by Giles and others (2007) using airborne laser and radar altimeters, and Connor and others (2009) using an airborne laser and spaceborne radar altimeter. In both cases, the elevation differences were comparable to Arctic snow depths from climatology.

The physical properties of snow determine its dielectric properties; previously the penetration characteristics of $\mathrm{Ku}$ band radar through snow on Antarctic sea ice using a sledgeborne radar were investigated by Willatt and others (2010). They found that for a snowpack without metamorphic features the radar return usually originated at the snow/ice interface, and concluded that a similar in situ study over Arctic sea ice is necessary to confirm the assumption of radar penetration to the snow/ice interface. This investigation uses new field data to determine whether the snow/ice or air/snow interface was the dominant scattering surface for a Ku-band normal-incidence airborne radar altimeter on Arctic sea ice. 


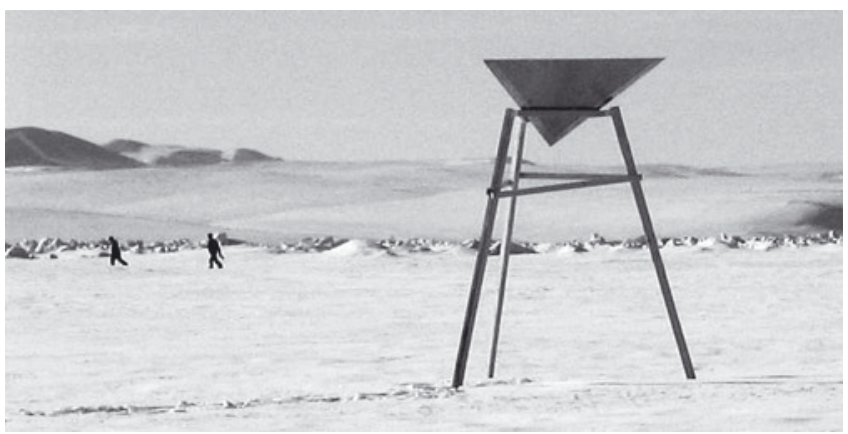

Fig. 1. Corner reflector deployed on snow-covered sea ice in a level-ice area during CryoVEx 2006 (Haas and others, 2006).

\section{DATA}

Data were obtained during the CryoSat Validation Experiment (CryoVEx) Bay of Bothnia, 2006 and 2008 campaigns with the European Space Agency's Airborne SAR (synthetic aperture radar) Interferometric Radar Altimeter System (ASIRAS) and the Danish National Space Centre's Airborne Laser Scanner (ALS), together with detailed ground measurements of the snow cover. The ASIRAS and ALS instruments were operated (often simultaneously) on board a Twin Otter aircraft, and the data were taken at the locations and times shown in Table 1 in the Bay of Bothnia and sea ice north of Alert, Ellesmere Island, Canada (2006 and 2008 campaigns). Trihedral corner reflectors of side length $1.4 \mathrm{~m}$ (Fig. 1) were deployed to provide a reference target above the snow surface for the radar. First-year ice is hereafter referred to as FYI, multi-year ice as MYI, and corner reflectors as CRs. The sites were chosen to have level surfaces (Haas and others, 2006).

The number of overflights in Table 1 refers to those during which ASIRAS data were obtained. The range of altitudes at which the CRs were overflown was 300-1100m. The corresponding footprint size across track, calculated using the $3 \mathrm{~dB}$ beamwidth of ASIRAS $\left(2.5^{\circ}\right)$, is $12-57 \mathrm{~m}$.

Ground measurements for the 2006 campaign were the most detailed, including snow-pit studies, ice surface elevation measurements, ice-thickness profiles, ice drilling and snow-depth measurements. In the Bay of Bothnia, there was almost no snow cover, so no snow measurements were carried out. In 2008, ice-thickness profiles and snow-pit studies were done. CR coordinates were measured using a hand-held GPS in all three campaigns. Ground measurements were not necessarily carried out on the same day as the ASIRAS flights (see Table 1).

The ASIRAS instrument uses a SAR/interferometric concept to achieve high-spatial-resolution radar altimetry, similar to the CryoSat-2 (Wingham and others, 2006) SAR Interferometric Radar Altimeter (SIRAL) sensor (Mavrocordatos and others, 2004). It uses a frequencymodulated radar with a centre frequency of $13.5 \mathrm{GHz}$ and bandwidth of $1 \mathrm{GHz}$ (Mavrocordatos and others, 2004), and is nadir-looking and pulse-limited (Lentz and others, 2002). Return echoes are processed to a series of 256 range bins; the range bin size is $10.98 \mathrm{~cm}$ (Cullen, 2010; http://cassiopea.estec.esa.int/cryo-http/CryoVEx/ Docs/CryoVEx_Airborne_Data_File_Formats_v2.6.1.pdf), making the range window $\sim 28 \mathrm{~m}$ long.

The ALS instrument is a Riegl laser scanner, with a range resolution of $5 \mathrm{~cm}$, and data logging of 40 (80) scans per second with 208 (113) shots per scan across a $60^{\circ}\left(45^{\circ}\right)$ cross-track swath for the 2008 \& 2006 (Bay of Bothnia) data (Helm and others, 2006; L. Stenseng and C.J. Andersen, unpublished information).

\section{ANALYSIS}

In order to determine from which surface the highestamplitude radar return originated, the snow/ice or air/snow interface, comparisons were made between the ASIRAS radar returns and measured snow depths. We calculated the apparent distance from the CR apex to the surface as seen in the ASIRAS data. This distance was then compared to the distances from the CR apex to the air/snow and snow/ice interfaces. Before this comparison could be made, it was necessary to correct for the fact that the ASIRAS was not directly above the CR. Figure 2 shows the geometry.

This is described by

$$
r_{\mathrm{CR}-Z}=\sqrt{r_{\mathrm{CR}}^{2}-\left(x_{\mathrm{CR}}-x\right)^{2}-\left(y_{\mathrm{CR}}-y\right)^{2}}
$$

and the corrective term is

$$
\Delta r=r_{\mathrm{CR}}-r_{\mathrm{CR}-Z} \text {. }
$$

In this investigation, $r_{\mathrm{CR}}$ was measured in the ASIRAS return echoes, while $r_{\mathrm{CR}-Z}$ is the elevation of the antenna above the CR apex. As shown in Figure 2, the range to the CR increases

\begin{tabular}{|c|c|c|c|c|c|}
\hline \multirow[t]{2}{*}{ Campaign } & \multicolumn{2}{|c|}{ Data collection dates } & \multirow[t]{2}{*}{ Location } & \multirow[t]{2}{*}{ Corner reflectors (CRs) } & \multirow[t]{2}{*}{ CR overflights } \\
\hline & Ground data & ASIRAS & & & \\
\hline Bay of Bothnia & Not applicable & $\begin{array}{l}13 \text { Mar } 2005 \\
14 \text { Mar } 2005\end{array}$ & $\begin{array}{l}64.9^{\circ} \mathrm{N} \\
24.3^{\circ} \mathrm{E}\end{array}$ & Two on bare ice (west and east) & $\begin{array}{l}\text { West: } 10 \\
\text { East: } 9\end{array}$ \\
\hline 2006 & $\begin{array}{l}13 \text { May } 2006 \\
14 \text { May } 2006\end{array}$ & 10 May 2006 & $\begin{array}{l}82.6^{\circ} \mathrm{N} \\
62.3^{\circ} \mathrm{W}\end{array}$ & $\begin{array}{l}\text { Two on MYI (S1CR1 and S1CR2) } \\
\text { Two on FYI (S2CR1 and S2CR2) }\end{array}$ & $\begin{array}{l}\text { S1CR1: } 7 \\
\text { S1CR2: } 10 \\
\text { S2CR1: } 7 \\
\text { S2CR2: } 8\end{array}$ \\
\hline 2008 & $\begin{array}{c}\text { 4-5 May } 2008(\mathrm{MYI}) \\
7 \text { May } 2008(\mathrm{MYI}) \\
1 \text { May } 2008(\mathrm{FYI}) \\
7 \text { May } 2008(\mathrm{FYI})\end{array}$ & 1 May 2008 & $\begin{array}{l}82.5^{\circ} \mathrm{N} \\
62.5^{\circ} \mathrm{W}\end{array}$ & $\begin{array}{l}\text { Two on MYI (MYIS and MYIN) } \\
\text { Two on FYI (FYIE and FYIW) }\end{array}$ & $\begin{array}{l}\text { MYIS: } 4 \\
\text { MYIN: } 4 \\
\text { FYIE: } 6 \\
\text { FYIW: } 6\end{array}$ \\
\hline
\end{tabular}

Table 1. Datasets used in this study 


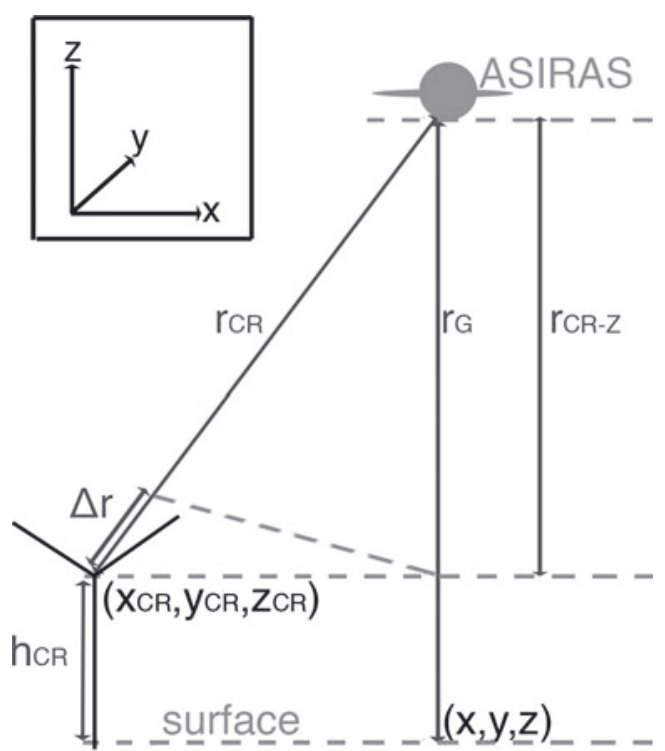

Fig. 2. Diagram showing the range from ASIRAS to the CR and surface (aircraft flight direction is into the page). The ranges measured to the CR and ground are $r_{\mathrm{CR}}$ and $r_{\mathrm{G}}$, respectively. The range that would be measured to the $\mathrm{CR}$ if it was at the antenna

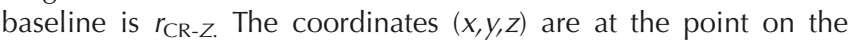
surface at the antenna baseline, and the coordinates $\left(x_{C R}, y_{C R}, z_{C R}\right)$ are at the apex of the CR. ASIRAS is at the origin. The $x$ and $y$ coordinates are in the across- and along-track directions, respectively, and the $z$ coordinates are measured from the altitude of the radar altimeter. The term 'surface' is deliberately vague as we are investigating to which surface, the air/snow interface or the snow/ ice interface, the radar ranges.

with distance from the antenna baseline. As a result, $r_{\mathrm{G}}-r_{\mathrm{CR}}$ decreases, so the CR height, $h_{\mathrm{CR}}$, appears to decrease. To correct for this effect, a term, $\Delta r$, accounting for the difference between $r_{\mathrm{CR}}$ and $r_{\mathrm{CR}-Z}$ was calculated and added to $r_{\mathrm{G}}$. In order to calculate $\Delta r$, the CR location must be accurately known; to ensure this was the case, we investigated the locations using the ALS data.

\section{Investigating corner reflector locations using ALS data}

Knowledge of the CR location is important for correcting the offset between the $\mathrm{CR}$ and the nadir track of the antenna, so we investigated the CR locations using the ALS data. We searched the ALS data for passes where the CR was visible; CRs were not visible in all passes. We believe this is due to the spacing between the samples on the ground (at least $1.5 \mathrm{~m}$ in the along- and across-track sampling for the 2006 and 2008 campaigns, and at least $1.5 \mathrm{~m}$ in the across-track and $0.75 \mathrm{~m}$ in the along-track direction for the Bay of Bothnia campaign), and due to specular reflections of the laser beam away from the aircraft. In several of the passes, one laser point close to the location measured with the GPS is higher than the scan points either side of it; this point can be identified as the CR. An example is shown in Figure 3.

An example of three ALS passes over the same CR is shown in Figure $3 \mathrm{~b}$. The average of the CR locations in the ALS data, and the GPS-determined position are also shown. For the 2006 and 2008 data the identification of the CR was straightforward: shots within a few meters of the GPS location, and with elevations $>1.0 \mathrm{~m}$ above the adjacent shots, were identified as originating from the CR. For the Bay of Bothnia data, the CR elevation did not appear as high. Points with elevations $>0.2 \mathrm{~m}$ above the adjacent shots were identified as the $\mathrm{CR}$, since the elevation difference between adjacent shots on the surrounding ice was only a few centimetres. For the Bay of Bothnia data, the ASIRAS data were collected on two days, so the positions were averaged for each day separately as shown in Table 2. The east reflector was only visible in ALS data on 14 March, but the average laser positions for the west on 13 and 14 March were separated by $5 \mathrm{~m}$. The average distance from the laser location to the GPS position for all the data was $2.25 \mathrm{~m}$.
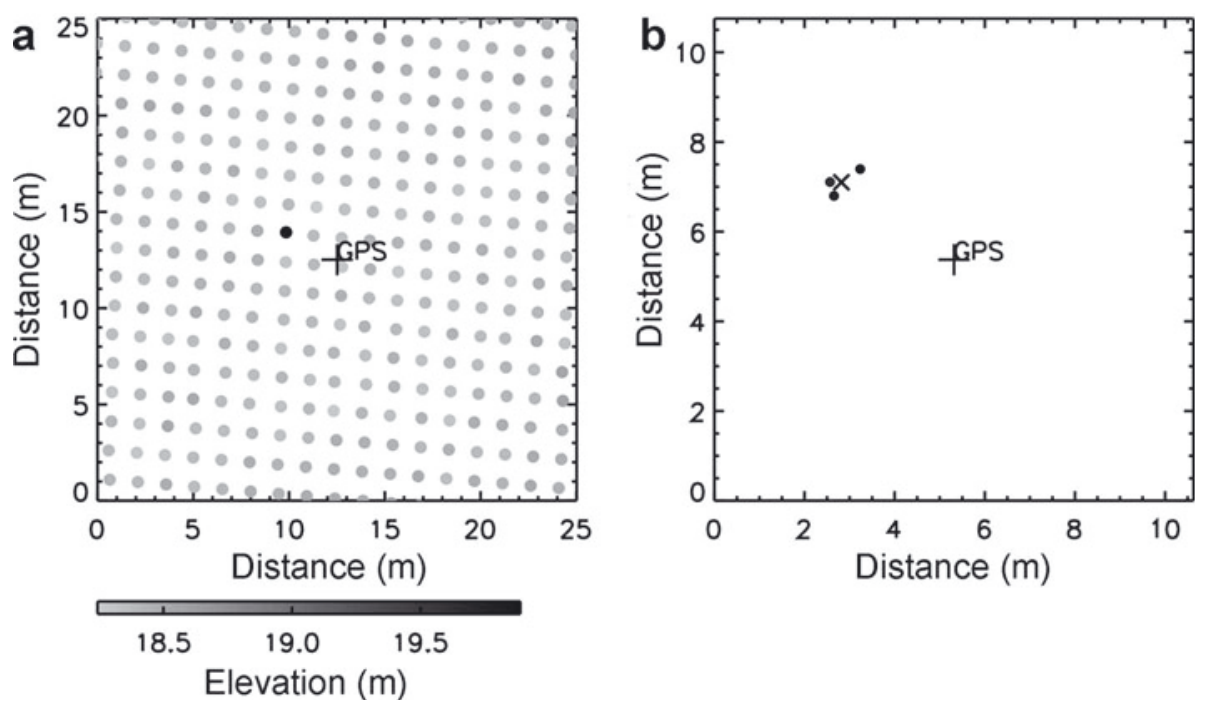

Fig. 3. (a) Elevations measured during one overflight of S2CR1 in 2006; each dot represents a laser shot. The snow surface is very flat and the black dot near the GPS position has an elevation $\sim 1.5 \mathrm{~m}$ greater than the adjacent points, hence it was identified as the CR, as the measured distance from the CR apex to the snow surface was $1.53 \mathrm{~m}$ (Haas and others, 2006). (b) Overlay of laser shots (circles) where the CR could be identified around S2CR1; it was visible in three passes. The ' $x$ ' shows the average position of the three shots identified as the CR in the ALS data. The ' + ' indicates the positions of the CR as measured by hand-held GPS. 


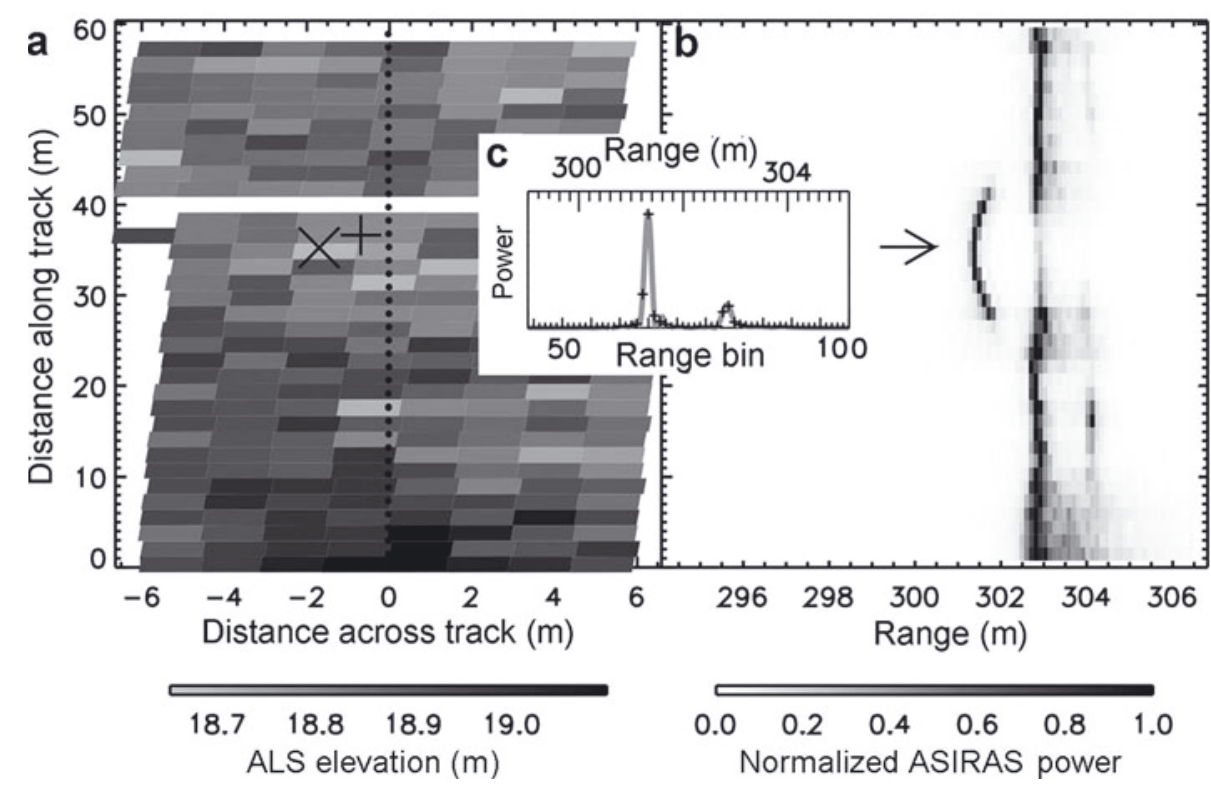

Fig. 4. ASIRAS and ALS data from an overflight of S1CR1 in 2006, dataset 02. (a) ALS elevation data with the ASIRAS baseline points overlaid. Missing data appear white. The ASIRAS footprint for this pass is $\sim 13 \mathrm{~m}$ in the across-track direction, and the spacing of stacked returns is $\sim 1.7 \mathrm{~m}$ in the along-track direction. ' + ' shows the position of the CR as measured with the hand-held GPS, and ' $x$ ' shows the average of the positions seen in the ALS data. (b) Z-scope plots of the power returned to ASIRAS against range. The arrow marks the echo where the CR appeared at the closest range. (c) This echo is shown: the fitted sinc function in grey, with the points sampled at $10.98 \mathrm{~cm}$ spacing overlaid in black; the power is normalized as in (b).

\section{Analysis of ASIRAS data}

In order to determine which is the dominant scattering surface for the radar, the air/snow or snow/ice interface, we looked at the range difference in the radar return between the peak from the CR and the peak from the surface. As discussed above, the offset between the CR and the antenna baseline, $x-x_{\mathrm{CR}}$ and $y-y_{\mathrm{CR}}$, must also be known. For CRs visible in the ALS data, we took the CR location to be at the average location in the ALS data. For CRs not visible in the ALS data, the GPS location was used. This location was used to calculate the CR $x_{C R}$ and $y_{C R}$ coordinates in Equation (1). Then the ASIRAS latitude and longitude data were transformed, using the Oblique Mercator transformation, into $x$ and $y$ values along the flight path. The same transformation was used for CR latitudes and longitudes.
An example is shown in Figure 4. Figure 4a shows the snow surface elevations measured by ALS with the ASIRAS baseline points superimposed; Figure 4b shows Z-scopes of the ASIRAS echoes.

In Figure 4 the ASIRAS data appear to show a hyperbolic $\mathrm{CR}$ response in range. In level $1 \mathrm{~b}$ data, the beams have been stacked with a slant range correction applied to each beam in the stack, so this hyperbola is not due to the true change of range from ASIRAS to the CR. Instead it is an artefact due to the stacking process, as the strong CR returns can be seen in more than one azimuth bin. Since the CR was visible in several echoes, for all the CR passes we took the return where the CR is at the closest range to ASIRAS (shown with an arrow in Fig. 4). For all the return echoes where the CR was at least an order of magnitude above the noise,

Table 2. ALS passes of CRs, for determining CR location

\begin{tabular}{|c|c|c|c|c|}
\hline Campaign & $\begin{array}{c}\text { Site and CR } \\
\text { (date for Bothnia) }\end{array}$ & Passes where CR visible & $\begin{array}{c}\text { Laser-to-GPS distance } \\
\left({ }^{\prime} x^{\prime} \text { to ' }+{ }^{\prime} \text { in Fig. } 3 b\right) \\
m\end{array}$ & $\begin{array}{c}\text { Distance between } \\
\text { laser points } \\
\mathrm{m}\end{array}$ \\
\hline \multirow[t]{4}{*}{ Bay of Bothnia } & East (13 March) & 0 & - & - \\
\hline & West (13 March) & 1 & 4.8 & - \\
\hline & East (14 March) & 2 & 1.8 & 0.3 \\
\hline & West (14 March) & 2 & 0.3 & 3.0 \\
\hline \multirow[t]{4}{*}{2006} & S1CR1 & 2 & 1.5 & 0.3 \\
\hline & S1CR2 & 1 & 3.3 & - \\
\hline & S2CR1 & 3 & 3.0 & 0.8 \\
\hline & S2CR2 & 4 & 3.9 & 1.4 \\
\hline \multirow[t]{4}{*}{2008} & FYIE & 1 & 1.0 & - \\
\hline & FYIW & 0 & - & - \\
\hline & MYIS & 3 & 1.7 & 2.0 \\
\hline & MYIN & 5 & 1.2 & 1.7 \\
\hline
\end{tabular}


estimated by taking the maximum power from the first $4 \mathrm{~m}$ of the echo (bins 0-37), we fitted a Gaussian-weighted sinc function to the echo (Fig. 4c). We used the return echo where the peak of the sinc function was at the smallest range to ASIRAS for further analysis.

Due to a known datation problem with ASIRAS, locations in the along-track direction can be shifted; datation errors of up to $0.25 \mathrm{~s}$ are reported for the 2006 data (L. Stenseng and C.J. Andersen, unpublished information), corresponding to $15 \mathrm{~m}$ at a typical flight velocity of $60 \mathrm{~m} \mathrm{~s}^{-1}$. We discarded data where the echo at the point of closest approach as given in the ASIRAS datation was more than twice the average distance from the laser to the GPS location (i.e. $4.5 \mathrm{~m}$ ), from the echo where the CR appeared at the smallest range (Fig. 5). Table 3 summarizes the ASIRAS overflights.

Figure 6 shows returns from dataset 09 from an overflight of S1CR1. The returns are complicated, showing several peaks in echo 1 and one broad peak in echo 2 around what we presume to be the CR response. It is difficult to analyse echoes such as these due to the complexity of their returns. Since the peak in echo 2 is closer, it is recorded as the echo at which the CR response appears at the closest range. The offset of the nadir point in echo 2 was $>4.5 \mathrm{~m}$ from the closest echo according to the ASIRAS datation, so these data were rejected as having a datation error.

\section{Depths of dominant scattering surfaces}

The depth of the dominant scattering surface below the CR apex was measured for each flight in which the CR was visible in the ASIRAS data. Two corrections were applied to the echoes. Firstly, using Equation (1), it can be seen it is necessary to correct for the effect of the offsets $x-x_{C R}$ and $y-y_{\mathrm{CR}}$ on the echo. We calculated $\Delta r$ from Equations (1) and (2) and shifted the return from $55 \mathrm{~cm}$ after the CR response to the last bin downwards. The $55 \mathrm{~cm}$ prevented the side lobes of the CR response from being shifted. The CR response was resampled using a sinc function to determine the range to the CR apex more precisely. The sinc-function fits are shown with the echoes in Figures 7-9 to provide a comparison for the dominant scattering surfaces seen in the radar return echoes.

Secondly, the velocity of the radar is slower through snow than through air; the averages of snow densities measured in the snow pit nearest each CR were used to calculate the reduced velocity, except for the Bay of Bothnia where there

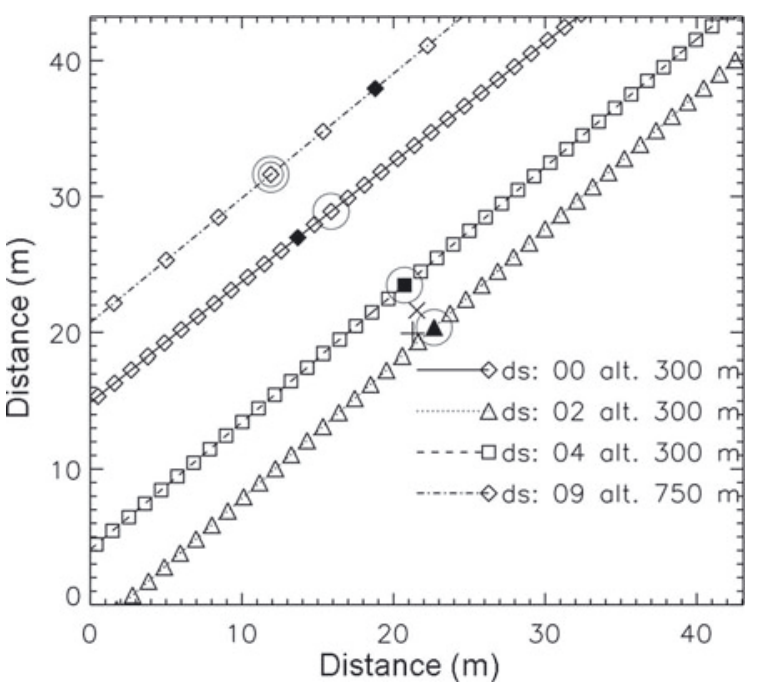

Fig. 5. Passes of the CR S1CR1 in 2006 data. The CR was visible in the four ASIRAS datasets listed with the altitudes of the overflights. Each open symbol shows the location of one ASIRAS echo. The filled symbols show the echoes where the CR appears at the smallest range in the echoes; the circles show the echoes at the point of closest approach according to the ASIRAS datation. A double circle indicates that the distance between the echo where the CR appears at the smallest range and the point of closest approach according to the ASIRAS datation is $>4.5 \mathrm{~m}$; these datasets are not used in the rest of the investigation. The ' $x$ ' symbol shows the CR location from the ALS data; the ' + ' symbol shows the location from the GPS data. The returns from datasets 02 and 09 are shown in Figures 4 and 6, respectively. In the legend, datasets 'ds: $n^{\prime}$ show individual passes over the CR.

was no snow cover. The reduced velocity correction was applied from the snow surface down. The mean velocity of the radar through snow as a percentage of the speed in a vacuum was $79 \%$ for 2008 and $82 \%$ for 2006 . The depths of the snow and ice surface from the CR apex were measured in the field and are shown in Figures 7-9. The correction, $\Delta r$, varied from 0 to $8 \mathrm{~cm}$, with a mean of $2 \mathrm{~cm}$, in the Bay of Bothnia; from 0 to $46 \mathrm{~cm}$, with a mean of $12 \mathrm{~cm}$, in 2006; and from 0 to $5 \mathrm{~cm}$, with a mean of $1 \mathrm{~cm}$, in 2008 .

For the Bay of Bothnia data, where there was a bare ice surface with no snow cover, the surface returns shown in Figure 7 coincide with the ice surface. This indicates that

Table 3. ASIRAS overflights of CRs

\begin{tabular}{lll}
\hline Campaign & Site and CR $\quad$ CR passes $\quad$ Passes where CR visible rejected due to \\
datation errors
\end{tabular}

$\%$

\begin{tabular}{|c|c|c|c|c|}
\hline \multirow[t]{2}{*}{ Bay of Bothnia } & West & 10 & 8 & 38 \\
\hline & East & 9 & 7 & 43 \\
\hline \multirow[t]{4}{*}{2006} & S1CR1 & 7 & 4 & 25 \\
\hline & S1CR2 & 10 & 3 & 33 \\
\hline & S2CR1 & 7 & 3 & 0 \\
\hline & S2CR2 & 8 & 5 & 20 \\
\hline \multirow[t]{4}{*}{2008} & FYIE & 6 & 2 & 50 \\
\hline & FYIW & 6 & 3 & 33 \\
\hline & MYIS & 4 & 3 & 67 \\
\hline & MYIN & 4 & 4 & 50 \\
\hline
\end{tabular}



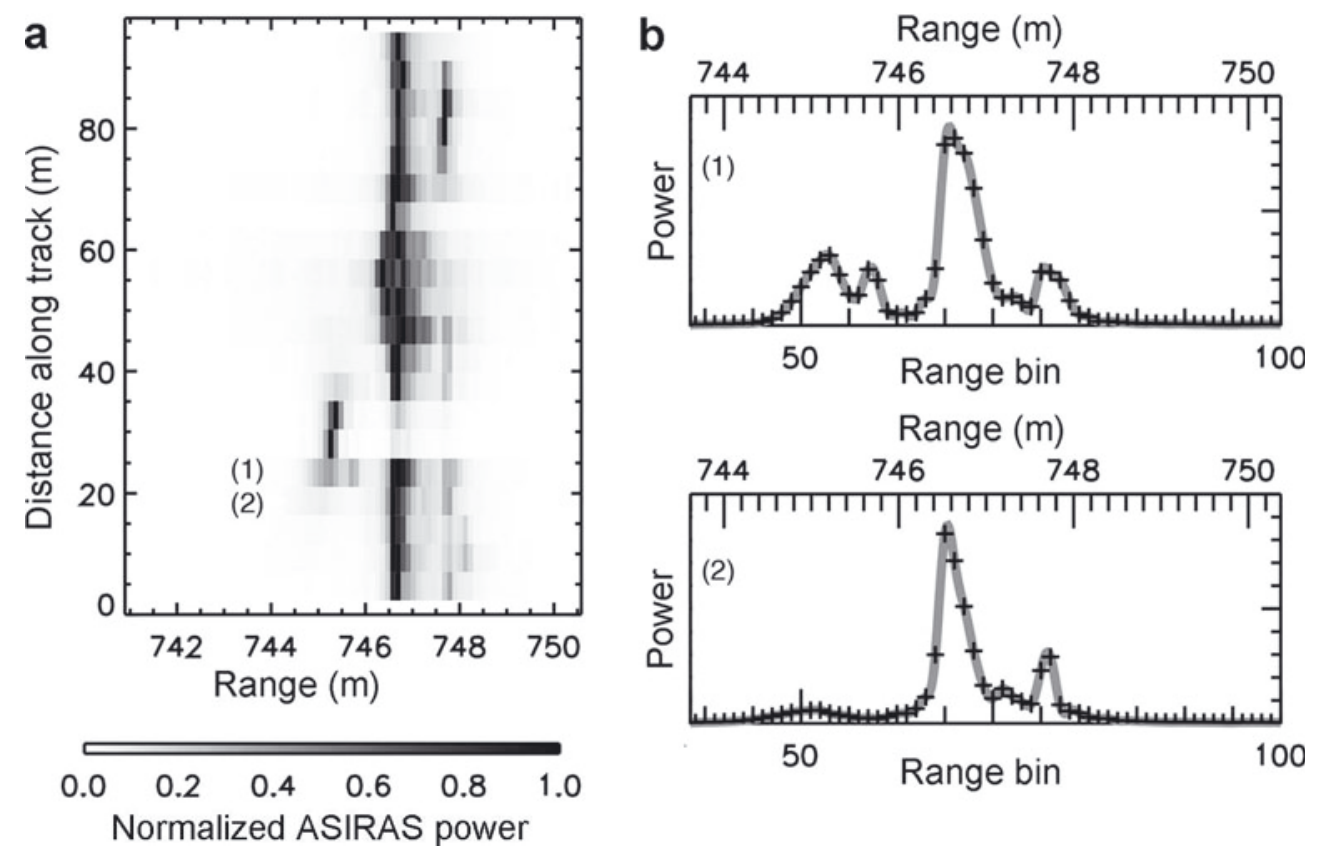

Fig. 6. (a) Radar returns from dataset 09 from S1 CR1 are displayed as for dataset 02 in Figure 4, except no ALS data were available. Echoes 1 and 2 are shown in (b), with the power normalized as in (a).

when no snow cover is present, the dominant scattering surface for the radar is the ice surface, as would be expected due to the large dielectric contrast between ice and air, even for low-salinity Baltic sea ice. The difference in ice surface height from the CR to the ASIRAS nadir point was calculated using an average of ALS points within a circle centred at the ASIRAS nadir point of diameter equal to the mean alongtrack spacing: $4.3 \mathrm{~m}$ for the Bay of Bothnia data.

For the 2006 and 2008 data, the snow depth at the nadir point of ASIRAS was approximated by taking the nearest snow-depth measurement from drillholes performed in the field. The difference in snow surface height from the CR to the ASIRAS nadir point was calculated using an average of ALS points within a circle centred at the ASIRAS nadir point of diameter equal to the mean along-track spacing: $2.3 \mathrm{~m}$ for 2006 and $3.2 \mathrm{~m}$ for 2008 data. We calculated the percentage of echoes for which the dominant scattering surface was closer to the snow/ice interface than the air/snow interface to compare the penetration of the radar in different years. We discuss the ASIRAS return echoes and the snow characteristics in snow pits near the CRs. Since the snow pits were not at the ASIRAS nadir points, and the snow pits show several snow characteristics such as radiation crusts and layering, it is not possible to specify which snow features cause which peaks in the ASIRAS data.

The radar returns obtained during CryoVEx 2006 are shown in Figure 8. Snow and weather characteristics reported here for 2006 are from Haas and others (2006).

When the field measurements were made, the measured snow temperatures were up to $-4{ }^{\circ} \mathrm{C}$. In snow pits near the CRs, a soft radiation crust was reported on the snow surface. Hard slab was also found in the snow pits, with the
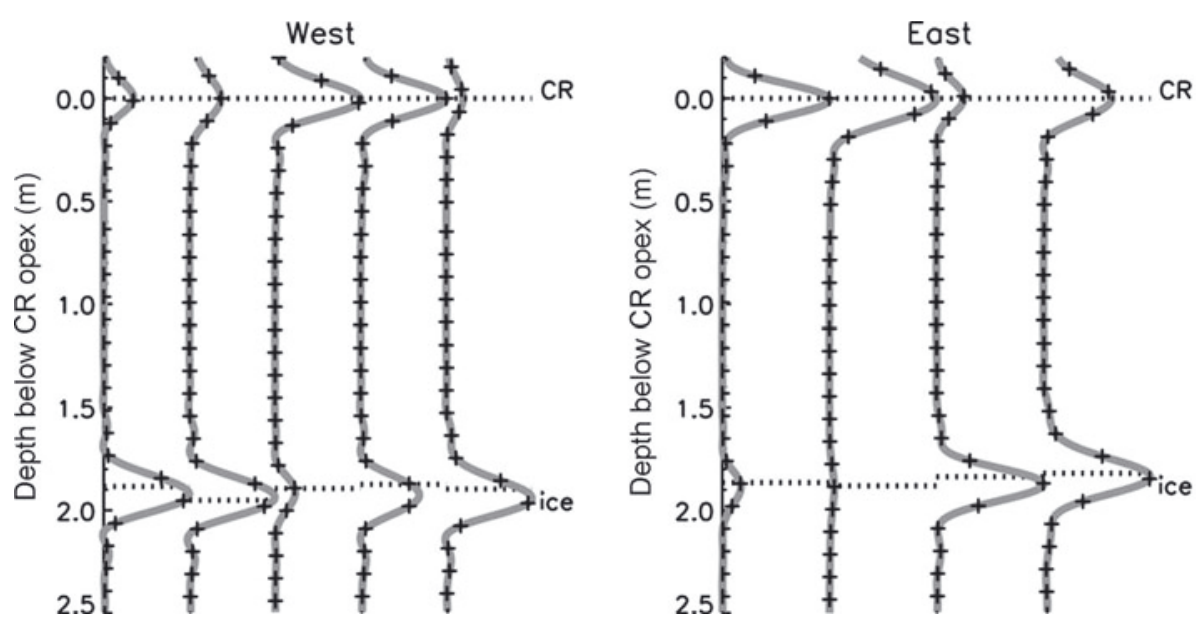

Fig. 7. ASIRAS returns from the Bay of Bothnia. The sinc functions are shown in grey, with the sampling points in the $10.98 \mathrm{~cm}$ range bins overlaid in black. The correction discussed above for the offset of the CR from the antenna baseline has been applied from $55 \mathrm{~cm}$ below the CR apex downwards. The position of the ice surface is marked as 'ice'; there is a clear agreement between this and the apparent ice surface in the returns. 

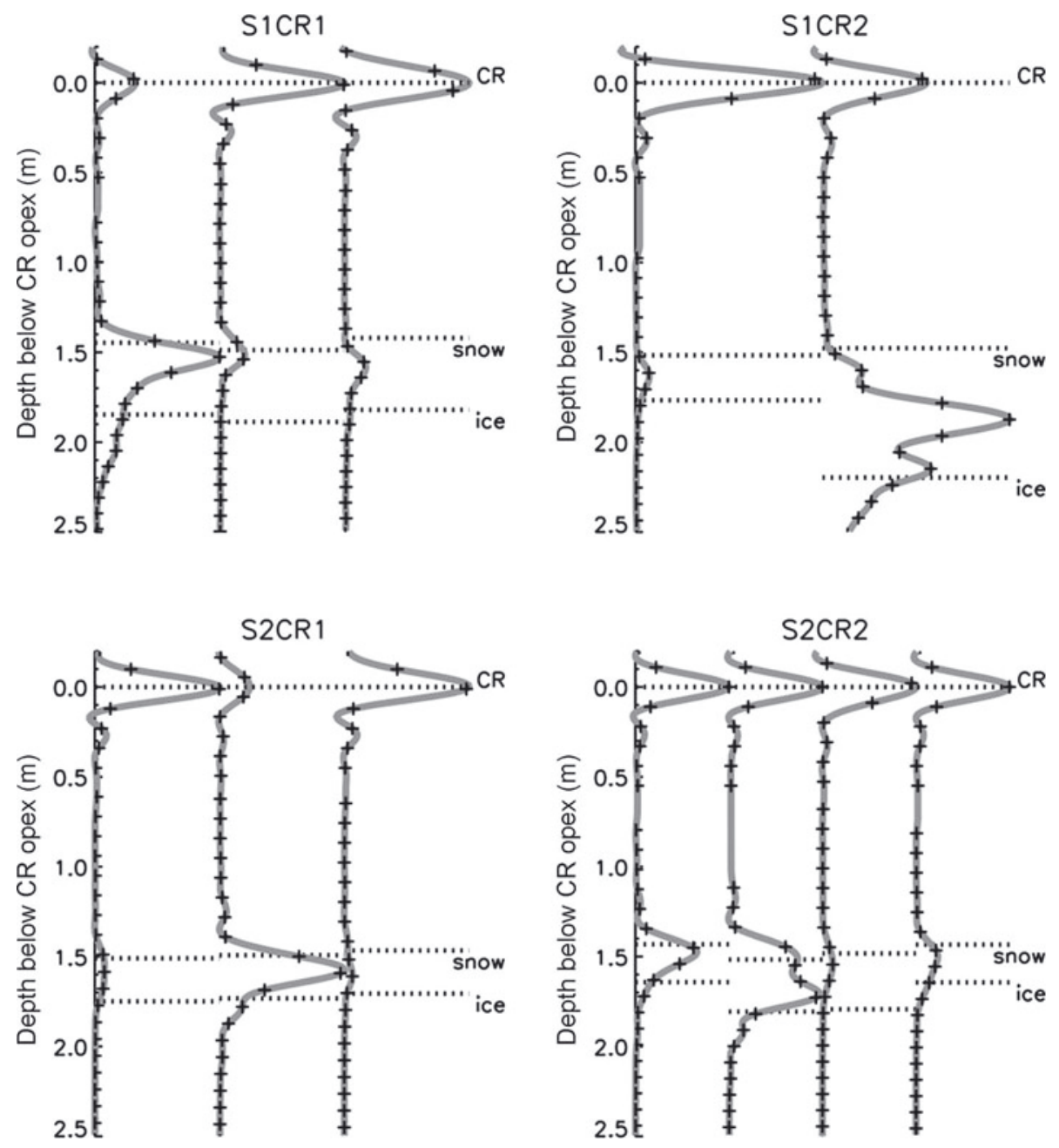

Fig. 8. ASIRAS returns from 2006, displayed as for the Bay of Bothnia (Fig. 7) but with the addition of the position of the snow surface measured in the field ('snow'). S1CR1 and S1CR2 are on MYI, S2CR1 and S2CR2 on FYI. The average snow density measured in snow pits near the CRs was 310, 240, 200, $260 \mathrm{~kg} \mathrm{~m}^{-3}$ at S1CR1, S1CR2, S2CR1 and S2CR2 respectively. Range bins from the snow surface downwards have been corrected for the velocity of propagation through the snow. For $25 \%$ of the returns, the dominant scattering surface for the radar is closer to the snow/ice than to the air/snow interface.

upper surface $\sim 11-15 \mathrm{~cm}$ below the snow surface. Figure 8 shows that in most cases the highest-amplitude peak in the radar return echo is close to the snow surface; for $25 \%$ of the returns in 2006, the dominant scattering surface of the radar is closer to the snow/ice interface than the air/snow interface, but for $75 \%$ the dominant scattering surfaces are closer to the air/snow interface. This is to be expected due to the altered microwave properties as temperatures approach freezing.

The radar returns from CryoVEx 2008 are shown in Figure 9; during this campaign the measured snow temperatures were up to $-8^{\circ} \mathrm{C}$. Snow measurements for the 2008 data are from Haas and others (2008). The snow densities measured in the snowpack at 1.96 and $2.06 \mathrm{~m}$ below the CR apex in FYI east (FYIE) were 400 and $270 \mathrm{~kg} \mathrm{~m}^{-3}$, respectively. The ASIRAS data show power returned from the air/ snow and snow/ice interfaces. In FYI west (FYIW) the average snow density was the highest of all the 2008 pits, and an ice layer was recorded in a snow pit near the CR at $8 \mathrm{~cm}$ above the ice surface. The return at MYI south (MYIS) is strange. The most likely explanation is that the snow and ice properties may be different at the ASIRAS nadir point from those at the nearest snow-depth measurement. As discussed further in the conclusions, we recommend denser spatial sampling of snow depth in future. The returns at MYI north (MYIN), where the snow density was lowest, are from close to the snow/ice interface. In our study on Antarctic sea ice we also showed that returns were more likely to originate from the snow/ice interface for low-density snow (Willatt and others, 2010). For the 2008 CryoVEx data, $80 \%$ of the radar returns for the dominant scattering surface were closer to the snow/ice interface than the air/snow interface (MYIS is not included in this percentage).

\section{CONCLUSIONS}

We showed radar return echoes from three CryoVEx campaigns to examine the penetration of Ku-band radar into snow cover on Arctic sea ice. We discarded data that showed datation problems and corrected the data for offsets between the CR locations to the antenna baseline, and the reduced velocity of radiation as it propagated through snow. The datation problem has now been resolved and so should not affect future campaigns.

The Bay of Bothnia provided us with a calibration site at which to look at the echoes when no snow cover was present. We showed that the dominant scattering surface in all the returns in the Bay of Bothnia campaign was the air/ice 

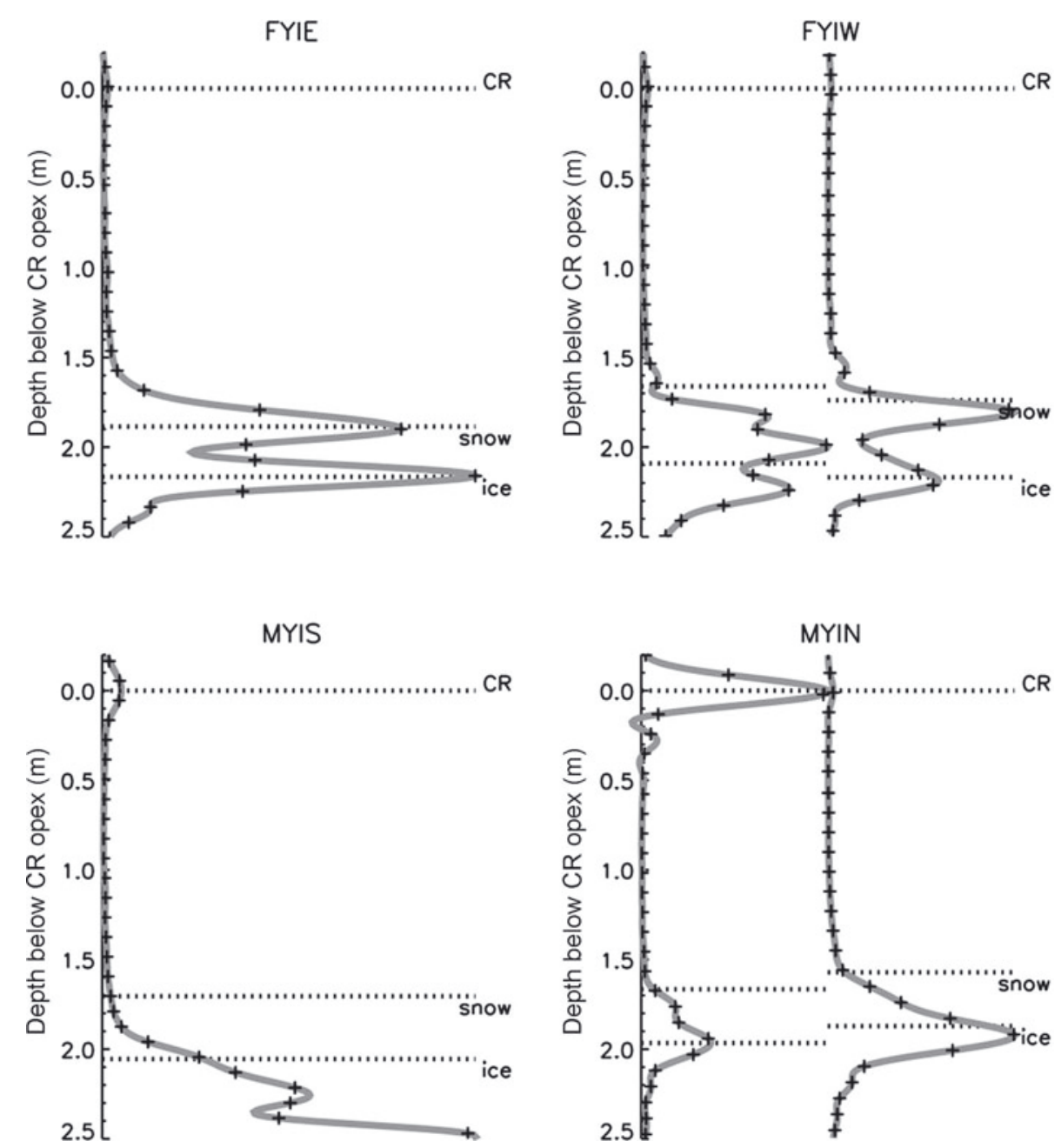

Fig. 9. ASIRAS returns from 2008. These returns are displayed as for 2006 (Fig. 8). The average snow density measured in snow pits at the CRs was 310, 360, 350 and $270 \mathrm{~kg} \mathrm{~m}^{-3}$ at FYIE, FYIW, MYIS and MYIN respectively. The temperatures measured in the snowpack were up to $-8^{\circ} \mathrm{C}$. For $75 \%$ of the returns, the dominant scattering surface for the radar is closer to the snow/ice interface than the air/snow interface, using positions measured in the field. The return from MYIS does not originate from within the ice; its appearance is probably due to the snow being much deeper where the radar return was obtained than at the closest snow measurement.

interface. In 2006, for $25 \%$ of the returns the dominant scattering surface for the radar was closer to the snow/ice interface than the air/snow interface. The snow temperatures were up to $-4^{\circ} \mathrm{C}$. The other returns show that the dominant scattering surface appears to be at or just below the snow surface. In 2008 the measured snow temperatures were up to $-8^{\circ} \mathrm{C}$, and for $80 \%$ of the returns the dominant scattering surface for the radar was closer to the snow/ice interface than the air/snow interface.

This indicates that the radar penetrates further into the snow cover at lower temperatures. It also shows that there is a need to repeat this experiment earlier in the year. The data presented here from the 2006 and 2008 campaigns are from May, but only satellite radar altimetry data from the winter (October-March) are used to determine sea-ice thickness (Laxon and others, 2003; Giles and others, 2008). It is clear that a dense set of snow-depth measurements (e.g. every 0.5 or $1 \mathrm{~m}$ ) around the CR to the width of the ASIRAS footprint would help to clarify the effect of variable snow depth on the results. Several detailed snow pits around each CR would allow a more detailed comparison of ASIRAS and field data.

A more detailed experiment should also be conducted using a ground-based radar (e.g. Willatt and others, 2010). However, the aircraft can provide data at the scales required for validation of CryoSat, and a combination of the two methods would provide a clearer picture. Improvements to the ASIRAS datation should provide better information for the co-location of radar and in situ data, in future.

\section{ACKNOWLEDGEMENTS}

We acknowledge the referees and scientific editor for their helpful comments that allowed us to improve this paper. R. Willatt is supported by a UK National Environmental Research Council studentship (grant No. NE/F006446/1). We thank the European Space Agency for the ASIRAS data, and the CryoVEx Bay of Bothnia, 2006 and 2008 teams.

\section{REFERENCES}

Beaven, S.G. and 8 others. 1995. Laboratory measurements of radar backscatter from bare and snow-covered saline ice sheets. Int. J. Remote Sens., 16(5), 851-876.

Connor, L.N., S.W. Laxon, A.L. Ridout, W.B. Krabill and D.C. McAdoo. 2009. Comparison of Envisat radar and airborne laser altimeter measurements over Arctic sea ice. Remote Sens. Environ., 113(3), 563-570. 
Cullen, R. 2010. ASIRAS product description CS-LI-ESA-G5-0371 issue 2.6.1. Noordwijk, European Space Agency/European Space Research and Technology Centre.

Garrity, K. 1992. Characterization of snow on floating ice and case studies of brightness temperature change during the onset of melt. In Carsey, F.D. and 7 others, eds. Microwave remote sensing of sea ice. Washington, DC, American Geophysical Union, 313-328. (Geophysical Monograph Series 68.)

Giles, K.A. and 8 others. 2007. Combined airborne laser and radar altimeter measurements over the Fram Stait in May 2002 Remote Sens. Environ., 111(2-3), 182-194

Giles, K.A., S.W. Laxon and A.L. Ridout. 2008. Circumpolar thinning of Arctic sea ice following the 2007 record ice extent minimum. Geophys. Res. Lett., 35(22), L22502. (10.1029/ 2008GL035710.)

Haas, C., J. Haapala, S. Hanson, L. Rabenstein, E. Rinne and J. Wilkinson. 2006. CryoVEx 2006: field report. ESA/ESTEC contract 18677/04/NL/GS, CCN 2, Bremerhaven, Alfred Wegener Institute for Polar and Marine Research.

Haas, C., S. Hanson and S. Hendricks. 2008. CryoVEx 2008: field report of in-situ validation measurements. ESA/ESTEC contract 18677/04/NL/GS, CCN 4, Bremerhaven, Alfred Wegener Institute for Polar and Marine Research.

Helm, V. and 6 others. 2006. CryoVEx 2004 and 2005 (Bay of Bothnia) data acquisition and final report. Bremerhaven, Alfred Wegener Institute for Polar and Marine Research.

Howell, S.E.L., J.J. Yackel, R. de Abreu, T. Geldsetzer and C. Breneman. 2005. On the utility of SeaWinds/QuikSCAT data for the estimation of the thermodynamic state of first-year sea ice. IEEE Trans. Geosci. Remote Sens., 43(6), 1338-1350

Howell, S.E.L., A. Tivy, J.J. Yackel, B.G.T. Else and C.R. Duguay, 2008. Changing sea ice melt parameters in the Canadian Arctic Archipelago: implications for the future presence of multiyear ice. J. Geophys. Res., 113(C9), C09030. (10.1029/ 2008JC004730.)
Kwok, R., H.J. Zwally and D. Yi. 2004. ICESat observations of Arctic sea ice: a first look. Geophys. Res. Lett., 31(16), L16401. (10.1029/2004GL020309.)

Laxon, S., N. Peacock and D. Smith. 2003. High interannual variability in sea ice thickness in the Arctic region. Nature, 425(6961), 947-950.

Lentz, H., H.-M. Braun, M. Younis, C. Fischer, W. Wiesbeck and C. Mavrocordatos. 2002. Concept and realization of an Airborne SAR/Interferometric Radar Altimeter System (ASIRAS). In IGARSS '02. International Geoscience and Remote Sensing Symposium, 24-28 June 2002, Toronto, Canada. Proceedings, Vol. 6. Piscataway, NJ, Institute of Electrical and Electronics Engineers, 3099-3101.

Markus, T., J.C. Stroeve and J. Miller. 2009. Recent changes in Arctic sea ice melt onset, freezeup, and melt season length. J. Geophys. Res., 114(C12), C12024. (10.1029/2009JC005436.)

Mavrocordatos, C., E. Attema, M. Davidson, H. Lentz and U. Nixdorf. 2004. Development of ASIRAS (Airborne SAR/ Interferometric Altimeter System). In IGARSS '04. International Geoscience and Remote Sensing Symposium, 20-24 September, Anchorage, Alaska. Proceedings, Vol. 4. Piscataway, NJ, Institute of Electrical and Electronics Engineers, 2465-2467.

Persson, P.O.G., C.W. Fairall, E.L. Andreas, P.S. Guest and D.K. Perovich. 2002. Measurements near the Atmospheric Surface Flux Group tower at SHEBA: near-surface conditions and surface energy budget. J. Geophys. Res., 107(C10), 8045. (10.1029/2000JC000705.)

Smith, D.M. 1998. Observation of perennial Arctic sea ice melt and freeze-up using passive microwave data. J. Geophys. Res., 103(C12), 27,753-27,769.

Willatt, R.C., K.A. Giles, S.W. Laxon, L. Stone-Drake and A.P. Worby. 2010. Field investigations of Ku-Band radar penetration into snow cover on Antarctic sea ice. IEEE Trans. Geosci. Remote Sens., 48(1), 365-372.

Wingham, D.J. and 15 others. 2006. CryoSat: a mission to determine the fluctuations in Earth's land and marine ice fields. Adv. Space Res., 37(4), 841-871. 